Chapman University

Chapman University Digital Commons

$11-16-2021$

\title{
The Acute and Persisting Impact of COVID-19 on Trajectories of Adolescent Depression: Sex Differences and Social Connectedness
}

Sabrina R. Liu

Elyssia Poggi Davis

Anton M. Palma

Curt A. Sandman

Laura M. Glynn

Follow this and additional works at: https://digitalcommons.chapman.edu/psychology_articles

Part of the Child Psychology Commons, Epidemiology Commons, Health Psychology Commons, Other Mental and Social Health Commons, Other Psychiatry and Psychology Commons, Other Psychology Commons, Personality and Social Contexts Commons, Psychiatric and Mental Health Commons, and the Psychological Phenomena and Processes Commons 
The Acute and Persisting Impact of COVID-19 on Trajectories of Adolescent Depression: Sex Differences and Social Connectedness

\section{Comments}

This article was originally published in Journal of Affective Disorders, volume 229, in 2021.

https://doi.org/10.1016/j.jad.2021.11.030

This scholarship is part of the Chapman University COVID-19 Archives.

Creative Commons License

(c) (i)

This work is licensed under a Creative Commons Attribution 4.0 License.

Copyright

The authors 
Research paper

\title{
The acute and persisting impact of COVID-19 on trajectories of adolescent depression: Sex differences and social connectedness
}

\author{
Sabrina R. Liu ${ }^{\text {a, b, *, Elysia Poggi Davis }}{ }^{\mathrm{c}, \mathrm{e}}$, Anton M. Palma ${ }^{\mathrm{d}}$, Curt A. Sandman ${ }^{\mathrm{e}}$, Laura M. Glynn ${ }^{\mathrm{b}}$ \\ ${ }^{a}$ Conte Center, Department of Pediatrics, UCI, ZOT 4475, Irvine, CA 92697, United States of America \\ ${ }^{\mathrm{b}}$ Department of Psychology, Crean College of Health and Behavioral Sciences, Chapman University, One University Drive, Orange, CA 92866, United States of America \\ ${ }^{\mathrm{c}}$ Department of Psychology, University of Denver, 2155 S Race St, Denver, CO 80210, United States of America \\ d Institute for Clinical and Translational Science, University of California, Irvine, 1301 Hewitt Hall, 843 Health Science Rd, Irvine, CA 92697, United States of America \\ ${ }^{\mathrm{e}}$ Department of Psychiatry \& Human Behavior, University of California, Irvine, 101 The City Dr S, Orange, CA 92868, United States of America
}

\section{A R T I C L E I N F O}

\section{Keywords:}

COVID-19

Adolescent

Depression

Mental health

Pandemic

Social

\begin{abstract}
A B S T R A C T
Background: The COVID-19 era is a time of unprecedented stress, and there is widespread concern regarding its short- and long-term mental health impact. Adolescence is a sensitive period for the emergence of latent psychopathology vulnerabilities, often activated by environmental stressors. The present study examined COVID$19^{\prime}$ s impact on adolescent depression and possible influences of different domains of social connectedness (loneliness, social media use, social video game time, degree of social activity participation).

Methods: A community sample of 175 adolescents ( $51 \%$ boys, mean age $=16.01$ years) completed questionnaires once before and twice during the COVID-19 pandemic. Piecewise growth modeling examined the acute (7 weeks) and persistent (8 months) effects of COVID-19 on depressive symptoms, and differences across sex and social connectedness.

Results: Significant increases in depressive symptoms followed pandemic onset for boys and girls. However, this increase was earlier and more pronounced among girls than boys, whose depression only increased significantly during the persistent period and to a lesser degree. Trajectories of depression were influenced by loneliness and social connections.

Limitations: Most participants had economic stability and minimal exposure to the virus. Exacerbation of depressive symptoms may be more severe in higher risk populations.

Conclusions: Adolescent depression levels have increased during COVID-19, and are higher for girls and those who are lonely. Enhanced screening and management for adolescent depression and social connectedness could play a critical role in mitigating the negative mental health fallout of COVID-19 and future pandemics within this population.
\end{abstract}

\section{Introduction}

Considered the most serious global public health crisis since the 1918 influenza pandemic, COVID-19 has infected over 231 million people at the time of this study (October 2021), 4.7 million of whom have died (WHO Coronavirus Disease (COVID-19) Dashboard, 2021). Experts warn that without fundamental changes to the ways in which humans interact with their environment, the future will bring more frequent, contagious, and lethal pandemics (UN News, 2020). There is widespread concern among health professionals and the general public about the mental health impact of the virus and associated stressors (e.g., illness and death of oneself or loved ones, unemployment and financial insecurity, disrupted everyday life).

The impact of COVID-19 on adolescent mental health is of particular concern, given that adolescence is a sensitive period for the emergence of mental health disorders, often brought on or exacerbated by stressful environmental factors (Barrocas and Hankin, 2011). In addition to the typical stressors that come with adolescence, those living through the pandemic must contend with a myriad of new COVID-19-related concerns, such as fear of infection, worry about the health of loved ones, disrupted future plans, missed rites of passage, school, finances, and interpersonal relationships (Ellis et al., 2020; Bagus et al., 2021). Indeed,

\footnotetext{
* Corresponding author at: Department of Psychology, Crean College of Health and Behavioral Sciences, Chapman University, One University Drive, Orange, CA 92866, United States of America.

E-mail address: sabliu@chapman.edu (S.R. Liu).
} 
cross-sectional research suggests that adolescents are experiencing unique pandemic-related stress (American Psychological Association, 2020; Ellis et al., 2020; Magson et al., 2020), higher levels of stress than other age groups (American Psychological Association, 2020), and increased prevalence of multiple mental health disorders (Guessoum et al., 2020). However, most studies on COVID-19-related depression to date are cross-sectional, and the few existing longitudinal studies that include pre-COVID data report mixed findings (Copeland et al., 2021; Magson et al., 2020; Zhang et al., 2020).

Adolescent social connectedness during the COVID-19 pandemic may be a key determinant of mental health. Emerging independence from parental figures and more reliance on peers for social connection and support is a hallmark of the adolescent developmental stage. Along with these changes comes more social stressors and increased social sensitivity, both of which are thought to increase susceptibility to depression (Flynn and Rudolph, 2011; Owens et al., 2019; Somerville, 2013). The COVID-19 pandemic has disrupted typical adolescent social functioning through wide-spread school closures, event cancellations, and social distancing policies. Unsurprisingly, research has shown that adolescents are concerned about disconnection from friends, as well as disruption to school, extra-curricular activities, and social events during the COVID-19 pandemic (Ellis et al., 2020; Magson et al., 2020). However, continued participation in social activities increases risk of exposure to COVID-19 and potentially increased worry and anxiety regarding exposure.

Learning more about online peer interactions among adolescents during the pandemic is critical to understanding social connectedness and its role in mental health. In today's world, virtually all U.S. adolescents are "hyperconnected" with their peers through digital mediums such as social media and online gaming (Anderson and Rainie, 2012; Colder Carras et al., 2017), and cross-sectional data indicate that adolescent time on social media has increased further during the pandemic (Ellis et al., 2020). There are conflicting findings and professional opinions regarding the impact of social media and/or social video game usage on adolescent mental health (Granic et al., 2014; Nesi and Prinstein, 2015; Ohannessian, 2009; Vannucci and McCauley Ohannessian, 2019). On one hand, these online social mediums present opportunities for social connection, support, skill building, entertainment, and learning. Conversely, they might also expose one to negative peer interactions or bullying, more social comparison, and stressful, harmful, or violent modeling or messaging.

Adolescence is also the developmental stage during which girls begin to demonstrate greater rates of depression compared to boys (Hankin et al., 1998; Rudolph, 2002; Salk et al., 2017; Slavich et al., 2020). One possible explanation is that puberty brings sex-differentiated hormonal and neurodevelopmental changes that create developmentally dependent vulnerabilities to various stressors (Conley et al., 2014; Copeland et al., 2019; Li et al., 2012; Salk et al., 2017). Evidence suggests these changes may render adolescent females more sensitive to stressors (Bale, 2006; Bourke and Neigh, 2011; Goel and Bale, 2009; Rudolph, 2002) and particularly those of an interpersonal nature (Conley et al., 2014; Rudolph, 2002; Slavich et al., 2020).

The emergence of depression can lead to chronic disability across the lifetime (Rudolph, 2017), and furthering understanding of how stress related to COVID-19 contributes to disease risk is critical for guiding surveillance and clinical intervention. The pandemic presents a natural experiment to study several important questions related to the contribution of stress exposure to adolescent depression. First, is the introduction of a universal stressor associated with increases in adolescent depression (Thapar and Rutter, 2019)? Second, do trajectories of depressive symptoms vary by sex, and by the degree and nature of social connectedness (e.g., loneliness, degree of social activity participation, social media use, social video game use) during the pandemic? Lastly, is the effect related to duration of the stressor? Studies comparing mental health using data from multiple assessments from before and during the pandemic can provide insight into the acute and persistent impacts of the pandemic on mental health; however, to the authors' knowledge, there has been no research of this nature to date focused on adolescent depression.

The goal of the present study was to longitudinally examine the acute (at seven weeks into the pandemic) and persistent (at eight months into the pandemic) effects of the COVID-19 pandemic on adolescent depressive symptoms in boys and girls. We predicted that there would be an increase in depressive symptoms from before to during COVID-19 and that this difference would be more pronounced for girls and for those who were lonelier. We had no a priori hypotheses pertaining to the relation between social activity participation, social media and video game use and depression.

\section{Methods}

\subsection{Study overview and context}

This analysis used data from a sample of adolescents enrolled in an ongoing longitudinal study of mental health in Southern California. The week of March 11, 2020 COVID-19 was officially declared a pandemic by the WHO and a national emergency by the U.S. President. By early April, social distancing, travel restrictions, and mask-wearing guidelines were in place. In California, the governor declared a state of emergency on March 4th, issued a stay-at-home order on March 19th, and closed all schools for the remainder of the school year on April 1st. The state began to roll back its stay-at-home order in early May, only to reverse much of the plans by early June as cases began to spike again. By mid-December, California was consistently breaking new state records of daily cases and death tolls, and many counties reported their Intensive Care Units had 0\% availability (AJMC Staff, 2020; Antczak and Thompson, 2020; WHO, 2020; Eby, 2021; Hoeven, 2020; Lin et al., 2020; Muccari et al., 2020; Ostrov and Ibarra, 2020; Reuters Staff, 2020; Tapp, 2020).

Longitudinal data used in this study were collected via three online surveys: The first assessment (T1) took place before the COVID-19 pandemic (on average, 2 years prior to state shutdown; range 5 years1 week prior), the second assessment (T2) took place approximately eight weeks after the initial state shutdown (range 6 to 12 weeks), and the third (T3) took place at roughly 8.5 months after the shutdown (range 8 to 9.25 months). All data were collected before COVID-19 vaccines were available to the public. All procedures were approved by the responsible institutional review board. A timeline of survey administration in relation to the COVID-19 pandemic is presented in the Supplementary Material.

\subsection{Participants}

Participants included 175 adolescents (51\% boys) whose mothers were originally recruited during pregnancy into a longitudinal study of child development. Participants ranged in age from 12 to 21 at the date of the first California shutdown $(M=16.01, S D=2.56)$. For the current study, the only inclusion criteria were for adolescents to belong to the original study cohort $(N=271)$ and to have completed all three assessments. Those that completed all three surveys were about 9 to 10 months younger on average than those who did not. The two subsamples did not differ across sex, income, or racial/ethnic identity. Further sample demographic information is reported in Table 1.

\subsection{Measures}

COVID-19-specific descriptive information was collected at T3 with a series of questions from the CoRonavIruS Health Impact Survey (CRISIS, 2020) Youth Self-Report Baseline Form, a measure developed by the National Institute of Mental Health, and Nathan Kline Institute.

Depressive Symptoms were assessed with the Children's Depression Inventory (CDI-2:SR [S] (Kovacs, 2011). The CDI-2 consists of 12 self-report items assessing various symptoms over the prior two weeks. 
Table 1

Participant Characteristics, COVID-19-related Health \& Financial Impact at 8 Months Post State Shutdown.

\begin{tabular}{ll}
\hline & Mean (SD), Median \\
& or \% \\
\hline Age (Mean) & 16.01 (2.56) \\
Sex (\% Female) & 49.1 \\
Racial/Ethnic Identity (\%) & \\
Latinx/Hispanic & 27.4 \\
Non-Hispanic White & 42.9 \\
Black/African American & 3.4 \\
Asian American & 6.9 \\
Multiethnic & 19.4 \\
School Type (\%; for those attending school at start of & \\
$\quad$ pandemic, $n=159)$ & \\
Middle School & 25.8 \\
High School & 40.3 \\
College & 27 \\
Other (home school, certificate program, vocational program) & 6.9 \\
Income-to-needs ratio (Median \%) & 443 \\
Internet Access in Home (\%) & 98.3 \\
Employment and earning status changes due to COVID-19 (\%) & \\
Lost job & 7.4 \\
Family member lost job & 6.3 \\
Reduced ability to earn money & 14.3 \\
Family member reduced ability to earn money & 26.3 \\
Exposure to COVID-19 (\%) & \\
Exposed to someone likely to have virus & 18.9 \\
Suspected of having the virus (tested positive, received medical & 6.3 \\
$\quad$ diagnosis, or had symptoms) & 3.4 \\
Member of household diagnosed & 21.7 \\
Someone close (non-household member) diagnosed & \\
\hline & \\
\hline & \\
\hline
\end{tabular}

Responses are summed for an overall score, which can range from 0 to 24 . The CDI-2 has been validated and widely used as an assessment tool with adolescent populations (Kovacs, 2011). In the current study, it showed strong internal consistency at each timepoint, with values ranging between 0.81 and 0.84 .

Loneliness was measured at T2 and T3 with the 8-item UCLA loneliness scale (RULS-8; Roberts et al., 1993). Scores can range from 0 to 24 , with greater scores indicating more loneliness. This measure has been used extensively with different adolescent populations (Goossens et al., 2014; Loades et al., 2020), and there was good internal consistency in the current study sample (alpha $=0.82$ ). Reported levels of loneliness at T2 and T3 were moderately correlated $(r=0.56 p<.01)$, and an average of the two scores was used.

Time spent per day engaging in social media was assessed at T2 and T3 with a question from the CRISIS asking how much time per day participants were spending on social media (e.g., FaceTime, Zoom, Facebook, Instagram, Snapchat, Twitter, TikTok). Participants responded on a 5point scale ranging from $1=$ "none" to $5=$ "more than $6 \mathrm{~h}$." Social media use at T2 and T3 were correlated $(r=0.49 p<.01)$, and an average of the two scores was used.

Time spent per day playing social video games was assessed at $\mathrm{T} 3$ with a question created for this study and based on formating of the CRISIS. Participants were asked how much time they spent per day (hours and minutes) playing video games with others over the course of the last two weeks.

Social activity participation was measured at T3 with a checklist created for this study, asking participants if they had done any of 16 different activities since the beginning of the pandemic. These endorsements were summed for a total score assessing participants' degree of social activity participation during COVID-19.

\subsection{Data analyses}

A piecewise conditional growth model was employed to model within-person change in depressive symptoms during two distinct time periods: from time of shutdown to seven weeks later (acute effect), and from seven weeks past the shutdown until approximately eight months into COVID-19 (persistent effect). We conceptualized sex and social connectedness as potential predictors of between-person differences in susceptibility to depressive symptoms. To test these hypotheses, we fit a model with an interaction term between sex and time to assess sex differences in trajectories of depressive symptoms in the acute and persistent periods (model 1). We then refit the model including each measure of social connectedness in a 3-way interaction with sex and time: loneliness*sex*time (model 2), social video game time*sex*time (model 3), social media use*sex*time (model 4), and social activity participation*sex*time (model 5). All models adjusted for participant age at the time of the shutdown (centered at the mean) to account for age-related variability in depressive symptoms. Model results were used to calculate mean CDI scores at each timepoint and mean change in CDI scores between timepoints, estimated at the median number of months from the shutdown for each assessment (T1: 27.25 months before; T2: 1.75 months after; T3: 8.25 months after); for models 2-4, mean CDI scores were estimated at the 25th ("low") and 75th ("high") percentiles of loneliness, social video game time, social media use time, and social activity participation. Because of emerging research suggesting that mental health during the pandemic may differ by exposure to COVID-19 and/or race/ethnicity (Guo et al., 2020; Lee and Singh, 2021), exploratory supplemental analyses (repeated-measures analyses of covariance) were employed to investigate if these variables were associated with degree of change in depression scores across time.

\section{Results}

\subsection{Sample characteristics}

Sample demographics and COVID-19-related information are reported in Table 1 . Twenty-six percent of the sample had a family member whose ability to earn money was reduced due to COVID-19, while almost one-fifth reported exposure to someone likely to have the virus, and $6 \%$ believed they had acquired COVID.

Figs. 1 and 2 illustrate self-reported participation in social activities and interpersonal relationships after the onset of the COVID-19 pandemic by sex. The overwhelming majority of participants reported engaging in social activities with non-household members during the pandemic. More popular activities included going to eat at restaurants outdoors and going inside others' homes. Notably, boys and girls did not significantly differ in their endorsement of any social exposure items except for going to the movies ( $17 \%$ of boys vs. $6 \%$ of girls). When these activities were summed, boys reported participating in an average of 6.03 activities, which was similar to girls' average of 6.23 activities.

Over half of participants reported using social media for $2-3 \mathrm{~h}$ or more per day and playing social video games for $3.4 \mathrm{~h}$ per day; sex differences emerged with girls spending significantly more time on social media $(F(1,173)=28.12, p<.001)$ and boys playing social video games more $(F(1,171)=23.84, p<.001)$. On average, girls reported that they spend closer to 4-6 h daily on social media (a value of 4 on the scale), while boys reported spending closer to $2-3 \mathrm{~h}$ (a value of 3 on the scale). Conversely, boys are spending much more daily time playing social video games at an average of 243 min compared to girls' daily average of $40 \mathrm{~min}$. There were no reported sex differences in loneliness.

\subsection{Trajectories of depressive symptoms}

Mean CDI scores and mean changes between timepoints were estimated from the growth models and are presented in Table 2 and graphically in Figs. 3 and 4. Model 1 shows that in the pre-COVID era, boys and girls had no significant differences in mean CDI scores (3.91 for boys, 4.35 for girls, $p=.39$ ). However, as seen in Fig. 3, girls experienced a significant increase in depressive symptoms during the acute period following the initial COVID-19-related state shutdown (mean change: +1.31 points, $p<.01)$, and boys did not $(+.03$ points, $N S)$. 


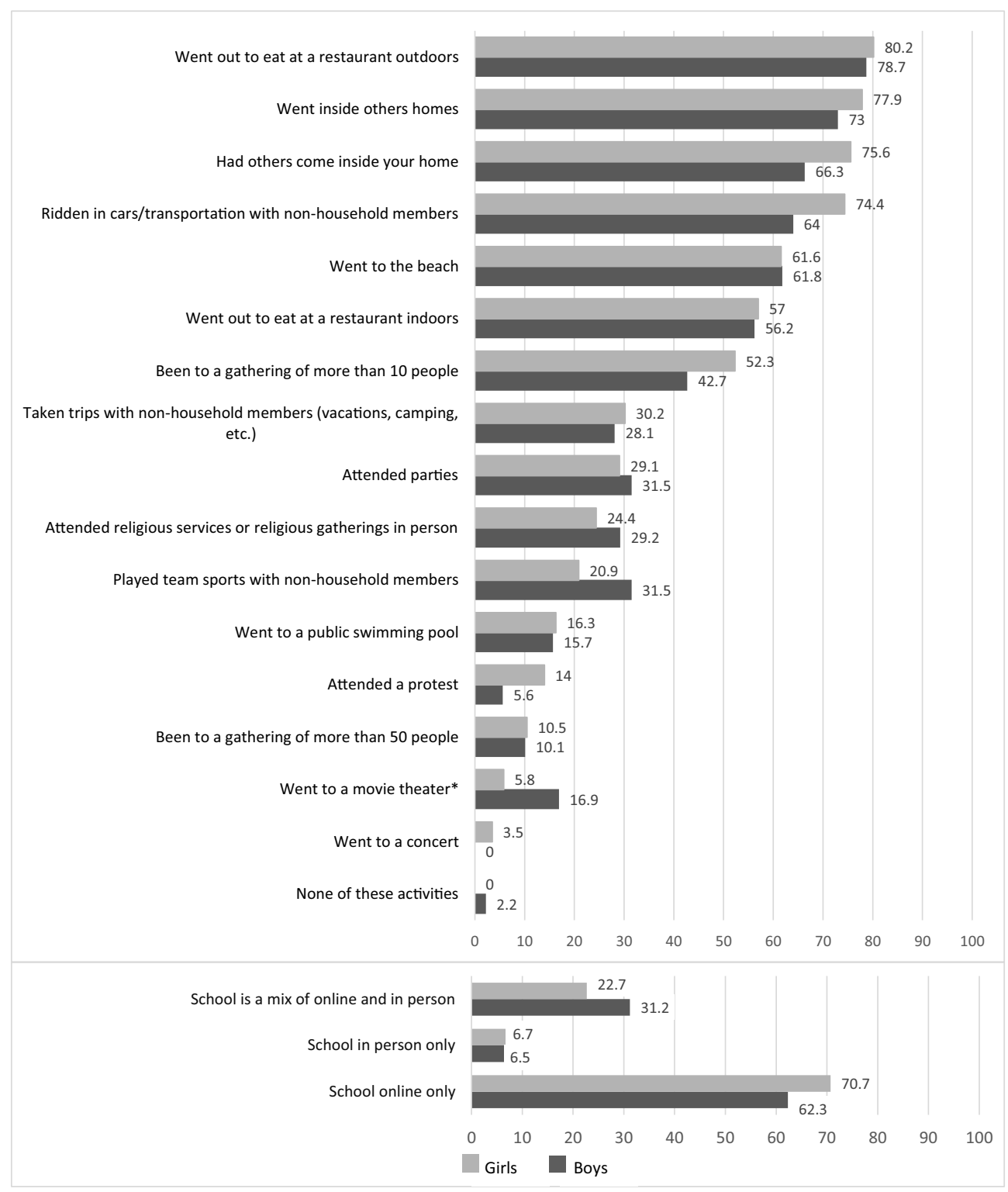

Fig. 1. Percentage of participants who endorsed participation in various social activities 8 months into state COVID-19 related shutdown.

Note. Asterisks in bar labels denote significant differences between boys and girls, ${ }^{*} p<.05$. Only respondents currently in school answered questions about school format.

During the persistent period (between 7 and 33 weeks into the pandemic), boys had a significant increase in depression levels (mean change: +1.02 points, $p<.05$ ). Meanwhile, girls did report a significant change in depression levels during the persistent period.

Models 2-5 (Table 2) examined change in depressive symptoms over time for boys and girls, and the influence of loneliness, time playing social video games, level of social media use, and degree of participation in social activities. Elevated loneliness was associated with higher levels of depressive symptoms at all timepoints, for both boys and girls (Fig. 4). Further, among adolescents with high levels of loneliness, sex differences in levels of depression were attenuated. For girls, more time on both social media and video games showed patterns of higher levels of depression across time. In particular, girls with higher levels of social video game time reported greater acute increases in depressive symptoms compared to girls with less social video game (difference $=1.62, p$ $<.01$ ). Additionally, girls who spent more time on social media had higher depressive symptoms during the pandemic compared to girls with lower social media use $(p<.05)$. Girls' high social media use was associated with a more pronounced acute increase in depressive symptoms (difference $=.28, p<.01$ ). In contrast to girls, social media use and video game time were not robust predictors of boys' depression over time. Lastly, throughout the pandemic, girls participating in more social activities experienced a steeper increase in depression symptoms compared to girls participating in fewer social activities (acute period difference $=.26, p<.01$; persistent period difference $=.48, p<.01$ ). Similar to social media use and social video game time, social activity participation was not a robust predictor of depression during the pandemic for boys.

The exploratory analyses testing associations of COVID-19 exposure and racial/ethnic identity with change in depression over time be found in the Supplemental Material.

\section{Discussion}

Existing literature suggests that the impact of stress on functioning can be more pronounced when the experience is prolonged (Goldfarb, 2020), but in comparison to research on acute collective stressors (for example, an earthquake or event of mass violence), there is very little 


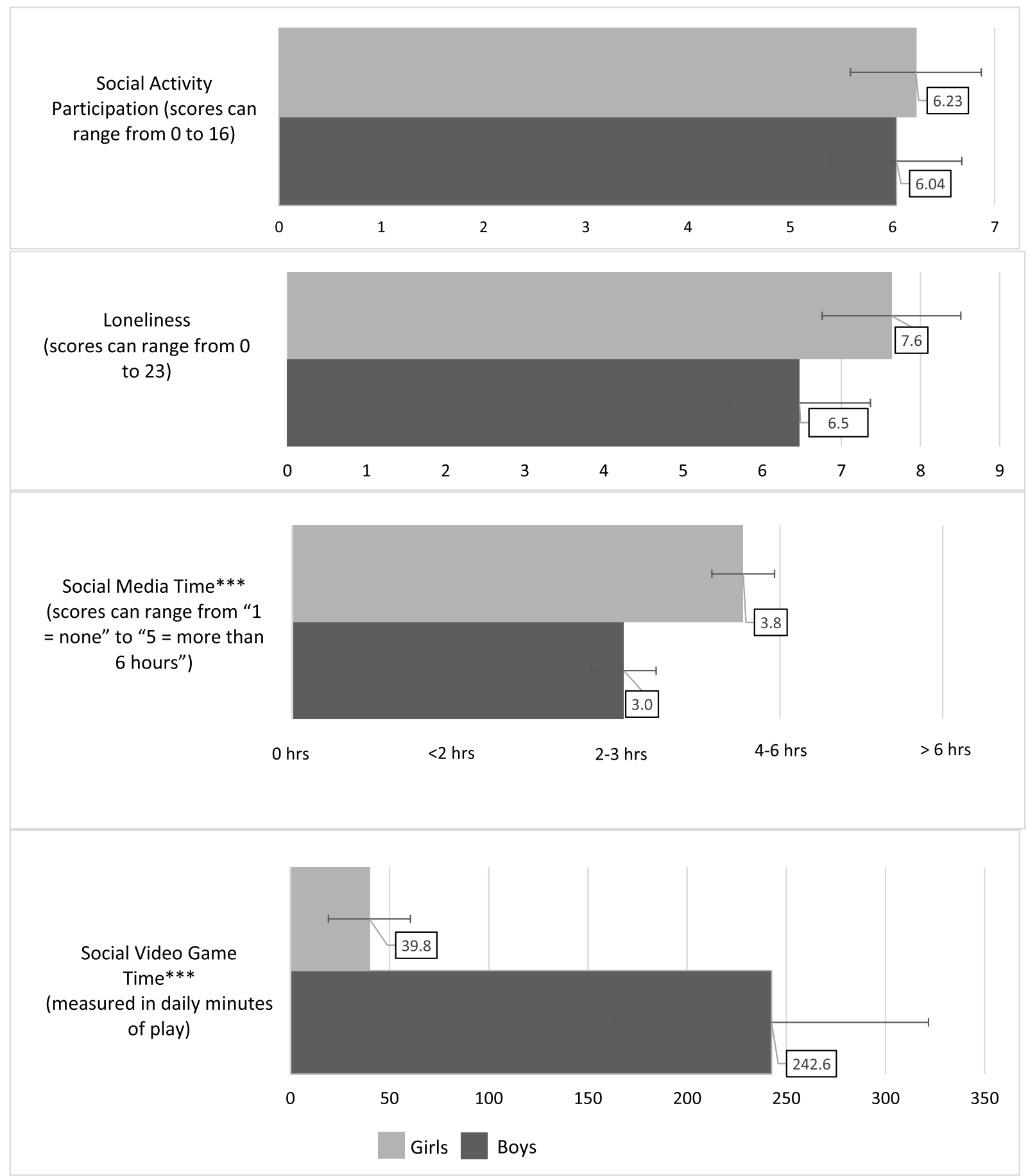

Fig. 2. Boys' and girls' average ratings of social activity participation, loneliness and time on social video games and social media.

Note. Asterisks denote significant differences across sex, ${ }^{* *} p<.001$. Social video game time and social activity participation were rated at T3; loneliness and social media time are averaged scores from $\mathrm{T} 2$ and $\mathrm{T} 3$ ratings.

research on how extended stressors like a pandemic impact mental health over time. In response to the ongoing public health emergency perpetuated by the COVID-19 pandemic, this study sought to answer critical questions about its acute and persistent effects on adolescent depressive symptoms. Longitudinal modeling identified increases in depressive symptoms among adolescents that have important implications for clinical assessment and treatment, particularly during the COVID-19 pandemic. Notably, we observed both acute and persistent increases in adolescent depression levels after the shutdown, and these changes differed by sex and social connectedness. Before the pandemic, girls and boys in our sample did not differ in their depression levels. However, after the shutdown, girls showed a significant uptick in depressive symptoms during the first seven weeks, which were maintained over the course of the next six or seven months. In contrast, boys did not initially exhibit increases in depressive symptoms after the shutdown, but their symptoms increased over the course of the next six months. Typically, adolescents score between 3 and 4 on the CDI-2:SR [S] (Kovacs, 2011), but the average depression scores of adolescents in this study eight months after the shutdown was approximately 5 for boys and 6 for girls, indicating elevated symptoms beyond what would 
Table 2

Boy's $(n=89)$ and girls' $(n=86)$ trajectories of depression from before to after COVID-19 pandemic onset

\begin{tabular}{|c|c|c|c|c|c|c|c|c|c|c|c|c|c|c|c|}
\hline \multirow[b]{2}{*}{ Timepoint } & \multicolumn{3}{|l|}{ Model 1} & \multicolumn{3}{|c|}{ Model 2 (+ loneliness) } & \multicolumn{3}{|c|}{ Model 3 (+ social video game time) } & \multicolumn{3}{|c|}{ Model 4 ( + social media use time) } & \multicolumn{3}{|c|}{$\begin{array}{l}\text { Model } 5 \text { (+ social activity } \\
\text { participation) }\end{array}$} \\
\hline & Boys & Girls & $\begin{array}{l}\text { Boys vs. } \\
\text { girls } p^{\mathrm{a}}\end{array}$ & Boys & Girls & $\begin{array}{l}\text { Boys vs. } \\
\text { girls } p^{\mathrm{a}}\end{array}$ & Boys & Girls & $\begin{array}{l}\text { Boys vs. } \\
\text { girls } p^{\mathrm{a}}\end{array}$ & Boys & Girls & $\begin{array}{l}\text { Boys vs. } \\
\text { girls } p^{\mathrm{a}}\end{array}$ & Boys & Girls & $\begin{array}{l}\text { Boys vs. } \\
\text { girls } p^{\text {a }}\end{array}$ \\
\hline & \multicolumn{3}{|l|}{ All } & \multicolumn{3}{|c|}{ Low loneliness ${ }^{\mathrm{b}}$} & \multicolumn{3}{|c|}{$\begin{array}{l}\text { Low social video game } \\
\text { time }^{\mathrm{b}}\end{array}$} & \multicolumn{3}{|c|}{$\begin{array}{l}\text { Low social media use } \\
\text { time }^{\mathrm{b}}\end{array}$} & \multicolumn{3}{|c|}{ Low social activity participation ${ }^{\mathrm{b}}$} \\
\hline \multicolumn{16}{|l|}{ Mean CDI score (SE) } \\
\hline Pre-COVID (T1) & $\begin{array}{l}3.91 \\
(0.37)\end{array}$ & $\begin{array}{l}4.35 \\
(0.36)\end{array}$ & & $\begin{array}{l}2.97 \\
(0.36)\end{array}$ & $\begin{array}{l}3.18 \\
(0.42)\end{array}$ & & $\begin{array}{l}3.41 \\
(0.72)\end{array}$ & $\begin{array}{l}4.21 \\
(0.42)\end{array}$ & & $\begin{array}{l}3.93 \\
(0.37)\end{array}$ & $\begin{array}{l}3.96 \\
(0.48)\end{array}$ & & $\begin{array}{l}4.32 \\
(0.44)\end{array}$ & $\begin{array}{l}4.70 \\
(0.46)\end{array}$ & \\
\hline Acute (T2) & $\begin{array}{l}3.94 \\
(0.36)\end{array}$ & $\begin{array}{l}5.66 \\
(0.36)\end{array}$ & $* *$ & $\begin{array}{l}2.57 \\
(0.35)\end{array}$ & $\begin{array}{l}4.14 \\
(0.41)\end{array}$ & * & $\begin{array}{l}4.15 \\
(0.67)\end{array}$ & $\begin{array}{l}5.30 \\
(0.43)\end{array}$ & & $\begin{array}{l}3.91 \\
(0.36)\end{array}$ & $\begin{array}{l}5.02 \\
(0.48)\end{array}$ & & $\begin{array}{l}4.42 \\
(0.42)\end{array}$ & $\begin{array}{l}5.86 \\
(0.45)\end{array}$ & \\
\hline Persistent (T3) & $\begin{array}{l}4.95 \\
(0.37)\end{array}$ & $\begin{array}{l}6.07 \\
(0.37)\end{array}$ & $*$ & $\begin{array}{l}3.59 \\
(0.37)\end{array}$ & $\begin{array}{l}4.86 \\
(0.43)\end{array}$ & & $\begin{array}{l}5.13 \\
(0.69)\end{array}$ & $\begin{array}{l}5.74 \\
(0.45)\end{array}$ & & $\begin{array}{l}4.93 \\
(0.37)\end{array}$ & $\begin{array}{l}5.42 \\
(0.49)\end{array}$ & & $\begin{array}{l}5.41 \\
(0.44)\end{array}$ & $\begin{array}{l}6.04 \\
(0.47)\end{array}$ & \\
\hline \multicolumn{16}{|l|}{ Change over time $(\mathrm{SE})^{\mathrm{c}}$} \\
\hline$\Delta$ Acute - Pre-COVID & $\begin{array}{l}0.03 \\
(0.29)\end{array}$ & $\begin{array}{l}1.31 \\
(0.27)^{* * *}\end{array}$ & $* *$ & $\begin{array}{l}-0.39 \\
(0.33)\end{array}$ & $\begin{array}{l}0.96 \\
(0.38)\end{array}$ & $* *$ & $\begin{array}{l}0.74 \\
(0.64)\end{array}$ & $\begin{array}{l}1.09 \\
(0.29)^{* * *}\end{array}$ & $* *$ & $\begin{array}{l}-0.02 \\
(0.31)\end{array}$ & $\begin{array}{l}1.06 \\
(0.39)^{*}\end{array}$ & ** & $\begin{array}{l}0.10 \\
(0.35)\end{array}$ & $\begin{array}{l}1.16 \\
(0.34)^{* *}\end{array}$ & $* *$ \\
\hline \multirow[t]{2}{*}{$\Delta$ Persistent - Acute } & $\begin{array}{l}1.02 \\
(0.33)^{*}\end{array}$ & $\begin{array}{l}0.41 \\
(0.34)\end{array}$ & $* *$ & $\begin{array}{l}1.02 \\
(0.38)\end{array}$ & $\begin{array}{l}0.72 \\
(0.45)\end{array}$ & $* *$ & $\begin{array}{l}0.97 \\
(0.64)\end{array}$ & $\begin{array}{l}0.44 \\
(0.41)\end{array}$ & $* *$ & $\begin{array}{l}1.02 \\
(0.34)\end{array}$ & $\begin{array}{l}0.40 \\
(0.46)\end{array}$ & $* *$ & $\begin{array}{l}0.99 \\
(0.40)\end{array}$ & $\begin{array}{l}0.18 \\
(0.42)\end{array}$ & $* *$ \\
\hline & & & & \multicolumn{3}{|c|}{ High loneliness $^{\mathrm{b}}$} & \multicolumn{3}{|c|}{$\begin{array}{l}\text { High social video game } \\
\text { time }^{b}\end{array}$} & \multicolumn{3}{|c|}{$\begin{array}{l}\text { High social media use } \\
\text { time }^{\mathrm{b}}\end{array}$} & \multirow{2}{*}{\multicolumn{3}{|c|}{ High social activity participation ${ }^{\mathrm{b}}$}} \\
\hline \multicolumn{14}{|l|}{ Mean CDI score (SE) } & & \\
\hline Pre-COVID (T1) & & & & $\begin{array}{l}4.70 \\
(0.41)\end{array}$ & $\begin{array}{l}5.11 \\
(0.32)\end{array}$ & & $\begin{array}{l}3.98 \\
(0.40)\end{array}$ & $\begin{array}{l}4.20 \\
(0.88)\end{array}$ & & $\begin{array}{l}3.57 \\
(0.49)\end{array}$ & $\begin{array}{l}4.50 \\
(0.37)\end{array}$ & & $\begin{array}{l}3.45 \\
(0.45)\end{array}$ & $\begin{array}{l}4.11 \\
(0.42)\end{array}$ & \\
\hline Acute (T2) & & & & $\begin{array}{l}5.47 \\
(0.37)\end{array}$ & $\begin{array}{l}6.53 \\
(0.34)\end{array}$ & & $\begin{array}{l}3.91 \\
(0.40)\end{array}$ & $\begin{array}{l}6.91 \\
(0.76)\end{array}$ & $* *$ & $\begin{array}{l}3.61 \\
(0.51)\end{array}$ & $\begin{array}{l}5.84 \\
(0.37)\end{array}$ & $* *$ & $\begin{array}{l}3.38 \\
(0.44)\end{array}$ & $\begin{array}{l}5.52 \\
(0.42)\end{array}$ & $* *$ \\
\hline Persistent (T3) & & & & $\begin{array}{l}6.45 \\
(0.39)\end{array}$ & $\begin{array}{l}6.75 \\
(0.36)\end{array}$ & & $\begin{array}{l}4.91 \\
(0.41)\end{array}$ & $\begin{array}{l}7.02 \\
(0.78)\end{array}$ & & $\begin{array}{l}5.07 \\
(0.52)\end{array}$ & $\begin{array}{l}6.28 \\
(0.39)\end{array}$ & & $\begin{array}{l}4.44 \\
(0.45)\end{array}$ & $\begin{array}{l}6.19 \\
(0.43)\end{array}$ & $*$ \\
\hline \multicolumn{16}{|l|}{ Change over time (SE) ${ }^{c}$} \\
\hline$\Delta$ Acute - Pre-COVID & & & & $\begin{array}{l}0.77 \\
(0.41)\end{array}$ & $\begin{array}{l}1.42 \\
(0.27)^{* * *}\end{array}$ & $* *$ & $\begin{array}{l}-0.07 \\
(0.31)\end{array}$ & $\begin{array}{l}2.71 \\
(0.84)^{* * *}\end{array}$ & $* *$ & $\begin{array}{l}0.04 \\
(0.37)\end{array}$ & $\begin{array}{l}1.34 \\
(0.27)^{* * *}\end{array}$ & $* *$ & $\begin{array}{l}-0.08 \\
(0.37)\end{array}$ & $\begin{array}{l}1.41 \\
(0.34)^{* * *}\end{array}$ & $* *$ \\
\hline$\Delta$ Persistent - Acute & & & & $\begin{array}{l}0.99 \\
(0.41)\end{array}$ & $\begin{array}{l}0.22 \\
(0.38)\end{array}$ & $* *$ & $\begin{array}{l}1.00 \\
(0.38)\end{array}$ & $\begin{array}{l}0.12 \\
(0.72)\end{array}$ & $* *$ & $\begin{array}{l}1.46 \\
(0.48)\end{array}$ & $\begin{array}{l}0.44 \\
(0.35)\end{array}$ & $* *$ & $\begin{array}{l}1.07 \\
(0.40)\end{array}$ & $\begin{array}{l}0.67 \\
(0.41)\end{array}$ & $* *$ \\
\hline $\begin{array}{l}\text { Differences by social } \\
\text { connectedness }^{\mathrm{d}}\end{array}$ & & & & \multicolumn{3}{|c|}{ High vs. low loneliness } & \multicolumn{3}{|c|}{ High vs. low social video game time } & \multicolumn{3}{|c|}{ High vs. low social media use time } & \multicolumn{3}{|c|}{$\begin{array}{l}\text { High vs. low social activity } \\
\text { participation }\end{array}$} \\
\hline \multicolumn{16}{|l|}{ Mean CDI score (SE) } \\
\hline Pre-COVID (T1) & & & & $\begin{array}{l}1.73 \\
(0.44)^{* * *}\end{array}$ & $\begin{array}{l}1.93 \\
(0.40)^{* * *}\end{array}$ & & $\begin{array}{l}0.57 \\
(0.77)\end{array}$ & $\begin{array}{l}-0.01 \\
(1.01)\end{array}$ & & $\begin{array}{l}-0.36 \\
(0.38)\end{array}$ & $\begin{array}{l}0.54 \\
(0.41)\end{array}$ & & $\begin{array}{l}-0.86 \\
(0.50)\end{array}$ & $\begin{array}{l}-0.59 \\
(0.51)\end{array}$ & \\
\hline Acute (T2) & & & & $\begin{array}{l}2.89 \\
(0.39)^{* * *}\end{array}$ & $\begin{array}{l}2.39 \\
(0.42)^{* * *}\end{array}$ & & $\begin{array}{l}-0.24 \\
(0.75)\end{array}$ & $\begin{array}{l}1.61 \\
(0.90)\end{array}$ & & $\begin{array}{l}-0.30 \\
(0.38)\end{array}$ & $\begin{array}{l}0.82 \\
(0.41)^{*}\end{array}$ & & $\begin{array}{l}-1.04 \\
(0.47)\end{array}$ & $\begin{array}{l}-0.34 \\
(0.49)\end{array}$ & \\
\hline Persistent (T3) & & & & $\begin{array}{l}2.86 \\
(0.41)^{* *}\end{array}$ & $\begin{array}{l}1.89 \\
(0.44)^{* * *}\end{array}$ & & $\begin{array}{l}-0.22 \\
(0.77)\end{array}$ & $\begin{array}{l}1.29 \\
(0.93)\end{array}$ & & $\begin{array}{l}0.14 \\
(0.39)\end{array}$ & $\begin{array}{l}0.86 \\
(0.42)^{*}\end{array}$ & & $\begin{array}{l}-0.97 \\
(0.49)\end{array}$ & $\begin{array}{l}-0.14 \\
(0.51)\end{array}$ & \\
\hline \multicolumn{16}{|l|}{ Change over time $(\mathrm{SE})^{\mathrm{c}}$} \\
\hline$\Delta$ Acute - Pre-COVID & & & & $\begin{array}{l}1.16 \\
(0.04)^{* * *}\end{array}$ & $\begin{array}{l}0.46 \\
(0.04)^{* * *}\end{array}$ & & $\begin{array}{l}-0.81 \\
(0.05)^{* * *}\end{array}$ & $\begin{array}{l}1.62 \\
(0.07)^{* * *}\end{array}$ & & $\begin{array}{l}0.06 \\
(0.04)^{*}\end{array}$ & $\begin{array}{l}0.28 \\
(0.04)^{* * *}\end{array}$ & & $\begin{array}{l}-0.18 \\
(0.04)^{* * *}\end{array}$ & $\begin{array}{l}0.26 \\
(0.04)^{* * *}\end{array}$ & \\
\hline$\Delta$ Persistent - Acute & & & & $\begin{array}{l}-0.03 \\
(0.04)\end{array}$ & $\begin{array}{l}-0.50 \\
(0.05)^{* *}\end{array}$ & & $\begin{array}{l}0.03 \\
(0.06)\end{array}$ & $\begin{array}{l}-0.32 \\
(0.06)^{* * *}\end{array}$ & & $\begin{array}{l}0.44 \\
(0.04)^{* * *}\end{array}$ & $\begin{array}{l}0.04 \\
(0.04)\end{array}$ & & $\begin{array}{l}0.08 \\
(0.04)\end{array}$ & $\begin{array}{l}0.48 \\
(0.04)^{* * *}\end{array}$ & \\
\hline
\end{tabular}

Note. ${ }^{*} p<.05, * * p<.01$.

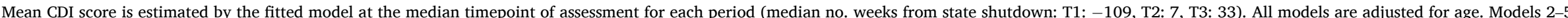

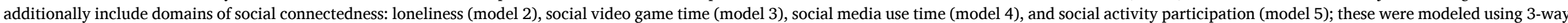
interactions between social exposure*sex*time.

a Differences by sex were compared using two-tailed Welch's $t$-test.

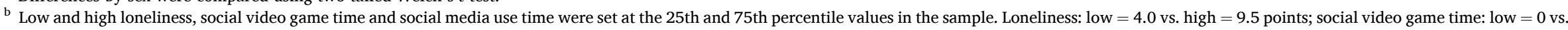
high $=5.2 \mathrm{~h}$; social media use time: low $=2-3$, high $=4-6 \mathrm{~h}$; social activity participation sum score: low $=4$, high $=8$ activities.

${ }^{\mathrm{c}}$ Mean change between timepoints were estimated using model-predicted CDI score at median weeks from shutdown, stratified by sex.

d p-values are for test of differences between high vs. low social connectedness variables in mean CDI score and change in mean CDI score over time. 


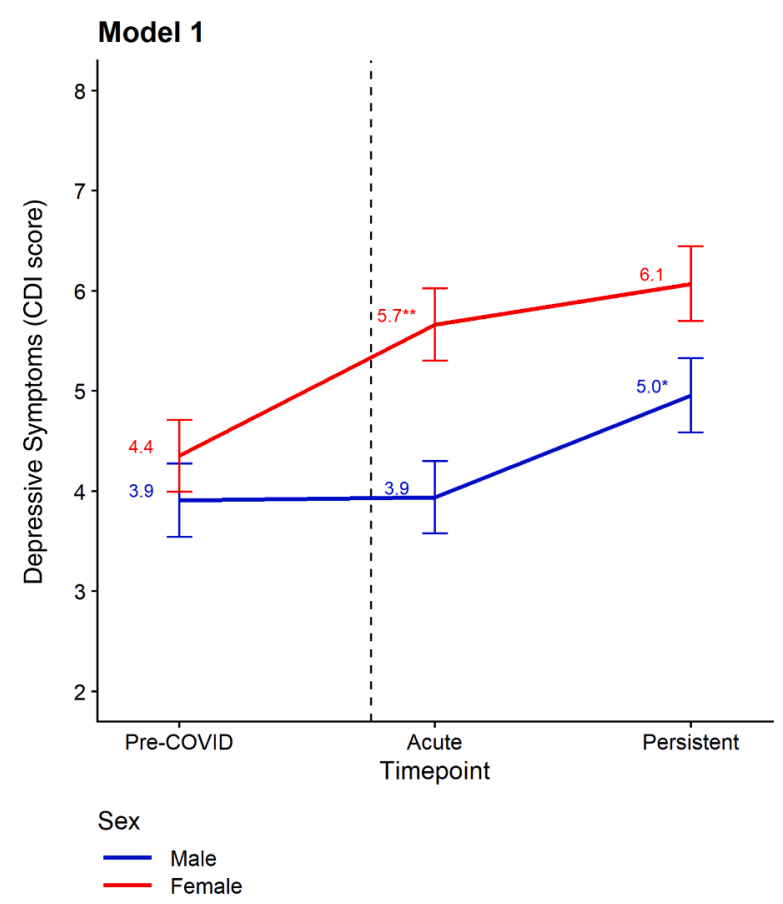

Fig. 3. Estimated mean depressive symptoms in the pre-COVID, acute and persistent periods by sex.

Note. Asterisks denote statistically significant changes in mean CDI score from the previous timepoint, ${ }^{*} p<.05,{ }^{* *} p<.01$. CDI scores were modeled using a conditional growth model (random intercepts for individual) adjusted for age at shutdown, with interaction between sex*time. Time is modeled using piecewise linear regression with knot at 7 weeks after shutdown. Dashed vertical line represents the state COVID-19 related shutdown date.

be expected in a non-pandemic population. Changes in depressive symptoms were present after adjusting for age, suggesting that the observed increases were over and above expected developmental changes.

Our results align with and build on a limited number of prospective findings of elevated depression in adolescents in the United States and abroad, in response to COVID-19 (Copeland et al., 2021; Huckins et al., 2020; Magson et al., 2020; Zhang et al., 2020). For example, Magson and colleagues (2020) also observed a more pronounced increase in depression levels for girls compared to boys from before to during COVID-19 (two months in). Our study extends Magson's finding by documenting that girls' depression levels remained elevated after an initial rise, while boys showed a delayed response, closing some of the observed gap. Taken together, the results support prior evidence and clinical theory suggesting that an increase in stress (in this case, stress related to COVID-19) and stress sensitivity during adolescence contributes to increases in depressive symptoms (Hankin, 2015; Somerville et al., 2010), and that girls may have heightened stress sensitivity compared to boys in adolescence (Bale, 2006; Bourke and Neigh, 2011; Conley et al., 2014; Goel and Bale, 2009; Rudolph, 2002), resulting in their faster and more extreme depressive reaction in response to COVID-19. The increases in depressive symptoms we observed over time were particularly important, given prior research showing that youth scores on self-report depression measures typically decline over time due to a repeated-measures effect (Long et al., 2020). Also notable were the sex differences present in both level and trajectories of adolescent depression, because while it is well-established that adolescents demonstrate large sex differences in depression as measured by diagnostic interviews, these differences do not necessarily emerge when examining adolescent depression symptoms through self-report questionnaires like the CDI (Long et al., 2020).

Although girls appear to be suffering more than boys in response to COVID-19, our results show that boys also are impacted and thus should not be overlooked in prevention and intervention efforts. Prior research suggests boys' delayed response may be related to higher levels of emotional regulation, lower levels of socioemotional awareness and/or societal norms and pressures for males to suppress negative emotions more so than girls (Deckert et al., 2020; Giel and Derntl, 2021; Hagler et al., 2016; Pollastri et al., 2018). Scholars have also questioned whether males may be more likely to respond to COVID-19 related stressors via externalizing behaviors that this investigation did not address, such as substance use (Giel and Derntl, 2021). Research examining adolescent externalizing disorders during COVID-19 could deepen understanding of the sex differences identified by the current study.

Given the dearth of mental health research on pandemics prior to COVID-19, it also is important to draw on literature from the field of disaster psychiatry to contextualize study results. To date, research of a longitudinal nature that considers possible sex differences has been limited. A recent meta-analysis found exposure to natural disasters was
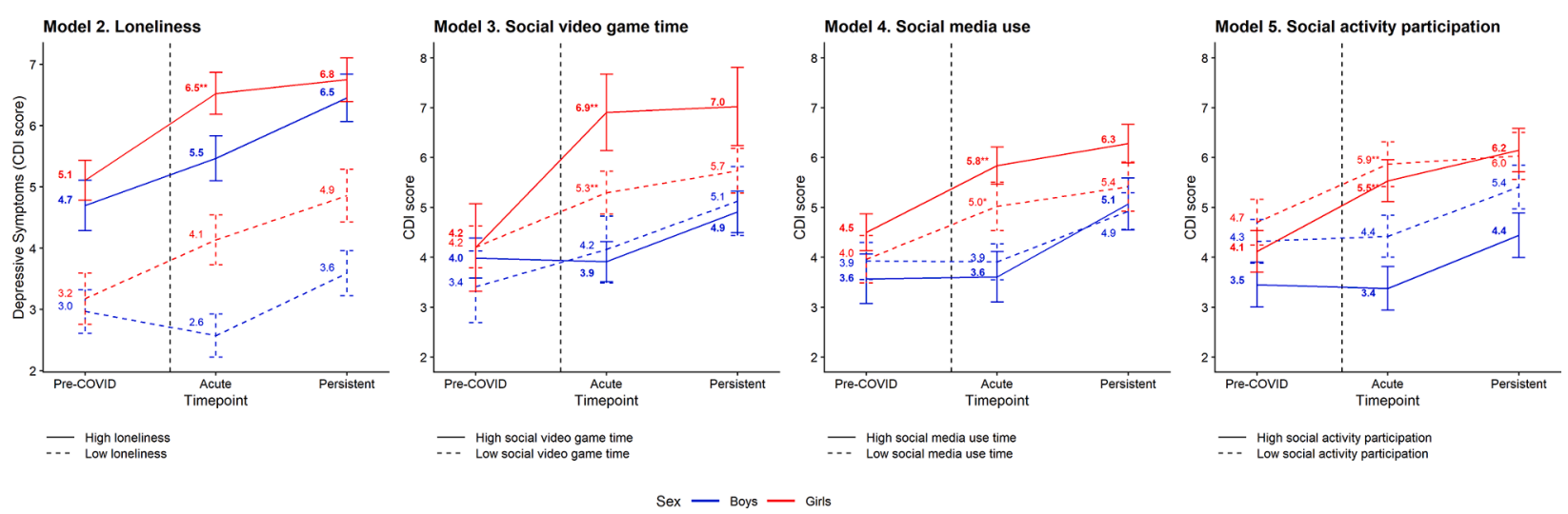

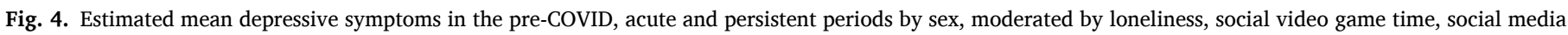
use time, and social activity participation.

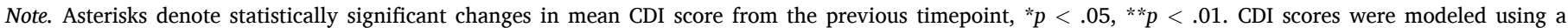

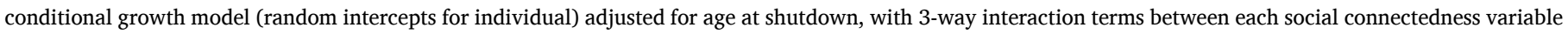

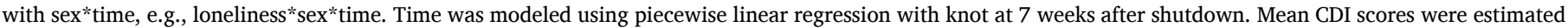

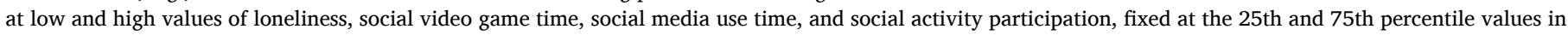

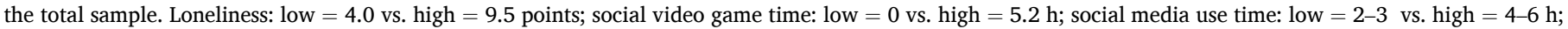
social activity participation: low $=4$ vs. high $=8$ activities. Dashed vertical line represents the state COVID-19 related shutdown date. 
linked to both internalizing and externalizing behaviors among youth; however, there was an insufficient amount of data to examine sex or racial/ethnic identity as moderators (Rubens et al., 2018). Several empirical studies have found links between being female and (compared to males) increased psychological distress, internalizing symptoms, or depression among adolescents exposed to the Great East Japan Earthquake (Hayashi et al., 2020), the spring 2011 tornado outbreak in Alabama and Missouri (Adams et al., 2014), and Hurricane Georges in Puerto Rico (Felix et al., 2011). One study found that posttraumatic stress levels were four times greater among children who experienced isolation and quarantine due to the $2009 \mathrm{H} 1 \mathrm{~N} 1$ pandemic versus those who did not, and no differences were observed across sex (Sprang and Silman, 2013). Conversely, research examining trajectories of youth posttraumatic stress symptoms after disasters has identified higher levels among girls, but no differences between boys and girls in level of change over time (Osofsky et al., 2015). Unlike the present study, none of these studies included pre-disaster mental health data, and thus were unable to examine change in mental health symptoms from pre to post or during disaster. Nonetheless, findings are mostly consistent with our results suggesting girls may be more vulnerable to such exposures. More longitudinal disaster research is needed to understand sex differences in trajectories of mental health, particularly depression, from before to during and after collectively stressful events.

This study also found that different domains of social connectedness were related to adolescent depressive symptoms during the COVID-19 pandemic, and sometimes the nature of these influences were sexdifferentiated. First, adolescents who were lonelier during the pandemic had higher levels of depression both before and throughout the pandemic (regardless of sex). Consistent with existing research conducted prior to and during COVID-19 (Hankin et al., 2015; Loades et al., 2020; Murata et al., 2020), our findings point to loneliness as a key indicator of who might be at higher risk for depression during a pandemic. For example, a recent cross-sectional study identified loneliness as a predictor of anxiety, posttraumatic stress, suicidal ideation or behavior, and prolonged grief among adolescents during COVID-19 (Murata et al., 2020). Additionally, feeling socially connected during the pandemic was protective against poor mental health in a prospective study of adolescents from before to during COVID-19 (Magson et al., 2020). Although directionality cannot be determined in the present study, previous research suggests loneliness is a consistent predictor of depressive symptoms among adolescents (Vanhalst et al., 2012), which aligns with the hypothesis that increased loneliness due to the COVID-19 pandemic is contributing to increased depression among adolescents.

We also examined adolescents' level of social activity participation during the pandemic, finding that it did not differentiate depression levels for boys or girls across the pandemic. More social activity participation was linked to greater increases in depression over time for girls. We cannot say with certainty the directionality of these associations, and further research is needed to discern whether maintaining social activity is a vulnerability factor for more depression among adolescents during a pandemic, or indicative of those adolescents who are generally more socially inclined and further impacted by COVID-19-related isolation.

Online social activity was related to girls' depressive symptoms over time. Higher levels of social media use were associated with higher depressive symptoms, while more social media use and social video game time were linked to greater acute increases in depression. These results build on prior cross-sectional research that found more social media usage related to more depression among adolescents during COVID-19 (Ellis et al., 2020; Murata et al., 2020). Our results support limited previous research suggesting that social video game usage influences girls' and boys' mental health differently; specifically, it has been associated with greater risk for anxiety among females and lower risk among males (Ohannessian, 2009; Ohannessian, 2019). Video games may differently impact boys' and girls' mental health for a variety of reasons, including misogyny and sexual harassment throughout social gaming spaces (Campbell, 2018; Clarke, 2019; O'Halloron, 2017).
Although directionality of the relation between online social activity and depression cannot be determined, prior research found that depression predicts more frequent social media use only among girls (not boys), and not the other way around (Heffer et al., 2019). This body of research highlights the need for further research on directionality of relations between various domains of social connectedness and depression, and differences across sex, particularly in the context of pandemics. It is also possible that domains of social connectedness (loneliness, social video game time, social media time, social activity participation) interact to influence depression. Future research can study this question through testing loneliness as a mediator or moderator of the association between social media use and video game time and depression.

\subsection{Limitations and future research directions}

This study has several limitations. Importantly, most study participants were in economically stable households and had minimal exposure to the virus. Studies need to examine adolescent depression in higher risk populations and study the unique and cumulative impact of other collective stressors co-occurring with COVID-19, including but not limited to COVID-19 exposure, racial injustice and political unrest (American Psychological Association, 2020). Longitudinal studies of depressive symptoms among socioeconomic and racially/ethnically diverse samples of adolescents across the U.S. during COVID-19 could more comprehensively address how COVID-19 intersects with social interactions, structural inequities, and socioeconomic disadvantage to pattern health outcomes. We were unable to assess the type of social media content or social video games adolescents were engaging with; more research is needed to examine these nuances, how well they capture social connectedness, and links to mental health. Lastly, there is evidence to suggest that exposure to COVID-19 itself and/or the stress of COVID-19 may alter brain structures associated with mental health (Valenzano et al., 2020). For example, one study found volumetric increases in brain regions commonly linked to internalizing disorders, in relation to a COVID-19-related lockdown (Salomon et al., 2021). Future research can build on the findings reported in this study by examining neurobiological mechanisms accounting for the relation between the COVID-19 pandemic and mental health.

\subsection{Implications}

Despite this study's limitations, its findings illustrate that increased attention to addressing depression among adolescents is essential during pandemics. Guidelines and toolkits for best practices in depression screening and intervention exist, including recommendations for both psychotherapy (i.e. cognitive behavioral therapy and interpersonal therapy) and pharmacotherapy (Clark et al., 2012). Strategies drawing on telehealth, mobile health (mhealth) and positive technologies (Riva et al., 2020), short-term treatment and self-guided interventions are available to implement with broad populations and must be tested in future research.

Our finding that loneliness exacerbated depression levels in the context of an extreme stressor underscores the importance of social support to adolescent mental health during the pandemic. During this time, more responsibility is falling on families to support one another and/or to find safe opportunities for social connection, for example, through socially-distanced and online activities and meetings. Programs and policies that provide financial and other types of resources for families are crucial and will likely have a ripple benefit of allowing them more emotional capacity to support one another. Additionally, youthserving organizations should also be aware of the increased risk of depression during this time, particularly among girls, and potential ways to mitigate risk including through increasing opportunities for social connection. Attention to social media and video game use is also indicated. Social media and gaming can be an outlet for adolescents to 
receive peer social support and engage with friends, but it may also contribute to worse mental health through exposure to online bullying, social comparison, or harmful modeling. Understanding an adolescents' individual pattern of engagement with social media and video games (particularly, whether or not they are playing with friends in a supportive manner) and the purpose it serves for them should be an important consideration in terms of its potential impact on their mental health.

Our results also suggest that participants are struggling to balance their need for social connection and interaction with physical health safety precautions during the pandemic. The majority of our participants were not living in complete "lockdown mode," despite public health recommendations, but rather endorsed participating (at relatively equal rates for boys and girls) in a variety of social activities that present different levels of infection risk. Therefore, it would seem that relying on adolescents to stay home and limit interpersonal reactions is not realistic; rather, emphasizing effective safety precautions (masks, social distancing, hand washing) and how to consider the relative safety of different social activities (i.e., going out to eat outside versus inside) may be more effective.

It is now clear that the COVID-19 pandemic will be a part of day-today life for many months to come, and perhaps longer. Furthermore, experts warn that society may be entering a new "era of pandemics," with more frequent, contagious, and lethal pandemics on the horizon (UN News, 2020). Our research suggests that adolescents, who are undergoing significant developmental and socioemotional changes, are experiencing increased depression levels and disrupted peer relationships during this global pandemic. Exposure to this persisting but acute and singular event is likely to have a permanent effect on society and especially on vulnerable populations such as children navigating adolescence. Extra attention to assessing and intervening with adolescent depression and social factors could play a critical role in mitigating the negative mental health fallout of COVID-19 and future pandemics within this population.

\section{Contributors}

Sabrina R. Liu, Laura M. Glynn, Anton M. Palma, Elysia P. Davis, Curt A. Sandman

\section{Declaration of Competing Interest}

The authors have no conflicts of interest to report.

\section{Acknowledgments}

This research was supported by the National Institutes of Health (P50 MH096889). The authors would like to express their heartfelt thanks to the study families for their continued participation in this study. We also would like to express gratitude to the entire team at the Chapman University Early Human and Lifespan development program, and in particular Kendra Leak, B.A. and Mareyna Simon, B.A. Your excellent work, dedication and enthusiasm are deeply appreciated. The authors have no conflicts of interest to disclose.

\section{Supplementary materials}

Supplementary material associated with this article can be found, in the online version, at doi:10.1016/j.jad.2021.11.030.

\section{References}

Adams, Z.W., Sumner, J.A., Danielson, C.K., Mccauley, J.L., Resnick, H.S., Grös, K., Paul, L.A., Welsh, K.E., Kenneth, J., 2014. Prevalence and predictors of PTSD and depression among adolescent victims of the spring 2011 tornado outbreak. J. Child Psychol. Psychiatry 55 (9), 1047-1055. https://doi.org/10.1111/jcpp.12220. AJMC Staff, 2020. A Timeline of COVID-19 Developments in 2020. AJMC.
American Psychological Association, 2020. Stress in America 2020: A National Mental Health Crisis. https://www.apa.org/news/press/releases/stress/2020/sia-mental-h ealth-crisis.pdf.

Anderson, J., Rainie, L., 2012. Main Findings: Teens, Technology, and Human Potential in 2020 | Pew Research Center. February 29. Pew Research Center: Internet \& Technology. https://www.pewresearch.org/internet/2012/02/29/main-findingsteens-technology-and-human-potential-in-2020/.

Antczak, J., Thompson, D., 2020. California COVID-19: 2 Million Confirmed Cases and Counting. December 24. Associated Press. https://apnews.com/article/pandemics -los-angeles-california-coronavirus-pandemic-0a2c9ac75b6a8c05706289bace1b402 4.

Bagus, P., Peña-Ramos, J.A., Sánchez-Bayón, A., 2021. COVID-19 and the political economy of mass hysteria. Int. J. Environ. Res. Public Health 18 (4), 1-15. https:// doi.org/10.3390/ijerph18041376.

Bale, T.L., 2006. Stress sensitivity and the development of affective disorders. Horm. Behav. 50 (4), 529-533. https://doi.org/10.1016/j.yhbeh.2006.06.033.

Barrocas, A., Hankin, B.L., 2011. Developmental pathways to depressive symptoms in adolescence: a multi-wave prospective study of negative emotionality, stressors, and anxiety. J. Abnorm. Child Psychol. 39 (4), 489-500. https://doi.org/10.1038/ jid.2014.371.

Bourke, C.H., Neigh, G.N., 2011. Behavioral effects of chronic adolescent stress are sustained and sexually dimorphic. Horm. Behav. 60 (1), 112-120. https://doi.org/ 10.1016/j.yhbeh.2011.03.011.

Campbell, C., 2018. Gaming's toxic men, explained. Polygon. https://www.polygon.com /2018/7/25/17593516/video-game-culture-toxic-men-explained.

Clark, M.S., Jansen, K.L., Anthony Cloy, J., 2012. Treatment of childhood and adolescent depression. Am. Fam. Physician 86 (5), 442-448.

Clarke, L., 2019. These Women Gamers are Fighting Back Against Toxic Online Culture. December 24. Washington Post. https://www.washingtonpost.com/graphics/2019/ sports/toxic-online-culture-women-esports/.

Colder Carras, M., Van Rooij, A.J., Van de Mheen, D., Musci, R., Xue, Q.L., Mendelson, T., 2017. Video gaming in a hyperconnected world: a cross-sectional study of heavy gaming, problematic gaming symptoms, and online socializing in adolescents. Comput. Hum. Behav. https://doi.org/10.1016/j.chb.2016.11.060.

Conley, C.S., Rudolph, K.D., Bryant, F.B., 2014. Explaining the longitudinal association between puberty and depression. Dev. Psychopathol. 24 (2), 691-701. https://doi. org /10.1017/S0954579412000259.

Copeland, W.E., McGinnis, E., Bai, Y., Adams, Z., Nardone, H., Devadanam, V., Rettew, J., Hudziak, J.J., 2021. Impact of COVID-19 pandemic on college student mental health and wellness. J. Am. Acad. Child Adolesc. Psychiatry 60 (1), 134-141. e2. https://doi.org/10.1016/j.jaac.2020.08.466.

Copeland, W.E., Worthman, C., Shanahan, L., Costello, E.J., Angold, A., 2019. Early pubertal timing and testosterone associated with higher levels of adolescent depression in girls. J. Am. Acad. Child Adolesc. Psychiatry 58 (12), 1197-1206. https://doi.org/10.1016/j.jaac.2019.02.007.

Deckert, M., Schmoeger, M., Auff, E., Willinger, U., 2020. Subjective emotional arousal: an explorative study on the role of gender, age, intensity, emotion regulation difficulties, depression and anxiety symptoms, and meta-emotion. Psychol. Res. 84 (7), 1857-1876. https://doi.org/10.1007/s00426-019-01197-z.

Eby, K., 2021. Coronavirus Timeline: Tracking Major Moments of COVID-19 Pandemic in San Francisco Bay area. January 6. ABC7 News. https://abc7news.com/timeline-of-c oronavirus-us-covid-19-bay-area-sf/6047519/.

Ellis, W.E., Dumas, T.M., Forbes, L.M., 2020. Physically isolated but socially connected: psychological adjustment and stress among adolescents during the initial COVID-19 crisis. Can. J. Behav. Sci. 52 (3), 177-187. https://doi.org/10.1037/cbs0000215.

Felix, E., Hernández, L.A., Bravo, M., Ramirez, R., Cabiya, J., Canino, G., 2011. Natural disaster and risk of psychiatric disorders in Puerto Rican children. J. Abnorm. Child Psychol. 39 (4), 589-600. https://doi.org/10.1007/s10802-010-9483-1.

Flynn, M., Rudolph, K.D., 2011. Stress generation and adolescent depression: contribution of interpersonal stress responses. J. Abnorm. Child Psychol. 39 (8) https://doi.org/10.1007/s10802-011-9527-1.

Giel, K.E., Derntl, B., 2021. The weaker sex? What we can learn from sex differences in population mental health during and beyond the COVID-19 pandemic. Eur. Arch. Psychiatry Clin. Neurosci. 0123456789, 1-2. https://doi.org/10.1007/s00406-02101312-5.

Guo, J., Feng, X.L., Wang, X.H., van IJzendoorn, M.H., 2020. Coping with COVID-19: exposure to COVID-19 and negative impact on livelihood predict elevated mental health problems in Chinese adults. Int. J. Environ. Res. Public Health 17 (11), 3857.

Goel, N., Bale, T.L., 2009. Examining the intersection of sex and stress in modeling neuropsychiatric disorders. J. Neuroendocrinol. 21 (4), 415-420. https://doi.org/ 10.1111/j.1365-2826.2009.01843.x.

Goldfarb, E.V., 2020. Participant stress in the COVID-19 era and beyond. Nat. Rev. Neurosci. 21 (12), 663-664. https://doi.org/10.1038/s41583-020-00388-7.

Goossens, L., Klimstra, T., Luyckx, K., Vanhalst, J., Teppers, E., 2014. Reliability and validity of the roberts UCLA loneliness scale (RULS-8) with Dutch-speaking adolescents in Belgium. Psychol. Belg. 54 (1), 5-18. https://doi.org/10.5334/pb.ae.

Granic, I., Lobel, A., Engels, R.C.M.E., 2014. The benefits of playing video games. Am. Psychol. 69 (1), 66-78. https://doi.org/10.1037/a0034857.

Guessoum, S.B., Lachal, J., Radjack, R., Carretier, E., Minassian, S., Benoit, L., Moro, M. R., 2020. Adolescent psychiatric disorders during the COVID-19 pandemic and lockdown. Psychiatry Res. 291, 113264 https://doi.org/10.1016/j. psychres.2020.113264.

Hagler, M., Grych, J., Banyard, V., Hamby, S., 2016. The ups and downs of selfregulation: tracing the patterns of regulatory abilities from adolescence to middle adulthood in a rural sample. J. Rural Ment. Health 40 (3-4), 164-179. https://doi. org/10.1037/rmh0000053. 
Hankin, B.L., 2015. Depression from childhood through adolescence: risk mechanisms across multiple systems and levels of analysis. Curr. Opin. Psychol. 4, 13-20. https:// doi.org/10.1016/j.copsyc.2015.01.003.

Hankin, B.L., Abramson, L.Y., Moffitt, T.E., Angell, K.E., Silva, P.A., McGee, R., 1998. Development of depression from preadolescence to young adulthood: emerging gender differences in a 10-year longitudinal study. J. Abnorm. Psychol. 107 (1), 128-140. https://doi.org/10.1037/0021-843X.107.1.128.

Hankin, B.L., Young, J.F., Abela, J.R.Z., Smolen, A., Jenness, J.L., Gulley, L.D., Technow, J.R., Gottlieb, A.B., Cohen, J.R., Oppenheimer, C.W., 2015. Depression from childhood into late adolescence: influence of gender, development, genetic susceptibility, and peer stress. J. Abnorm. Psychol. 124 (4), 803-816. https://doi. org/10.1037/abn0000089.

Hayashi, F., Sanpei, M., Ohira, T., Nakano, H., Okazaki, K., Yasumura, S., Nakajima, S. Yabe, H., Suzuki, Y., Kamiya, K., 2020. Changes in the mental health status of adolescents following the Fukushima Daiichi nuclear accident and related factors: Fukushima health management Survey. J. Affect. Disord. 260, 432-439. https://doi org/10.1016/j.jad.2019.09.045.

Heffer, T., Good, M., Daly, O., MacDonell, E., Willoughby, T., 2019. The longitudinal association between social-media use and depressive symptoms among adolescents and young adults: an empirical reply to Twenge et al. (2018). Clin. Psychol. Sci. 7 (3), 462-470. https://doi.org/10.1177/2167702618812727.

Hoeven, E., 2020. Newsom to Tighten California Stay-at-Home Order Before Holiday. July 1. CalMatters. https://calmatters.org/newsletters/whatmatters/2020/07/c alifornia-fourth-of-july-beaches-stay-at-home-order-newsom/.

Huckins, J.F., da Silva, A.W., Wang, W., Hedlund, E., Rogers, C., Nepal, S.K., Wu, J., Obuchi, M., Murphy, E.I., Meyer, M.L., Wagner, D.D., Holtzheimer, P.E., Campbell, A.T., 2020. Mental health and behavior of college students during the early phases of the COVID-19 pandemic: longitudinal smartphone and ecological momentary assessment study. J. Med. Internet Res. 22 (6) https://doi.org/10.2196/ 20185.

Kovacs, M., 2011. Children's Depression Inventory 2 (CDI 2), 2nd ed. Multi-Health Systems.

Lee, H., Singh, G.K., 2021. Monthly trends in self-reported health status and depression by race/ethnicity and socioeconomic status during the COVID-19 pandemic, United States, April 2020-May 2021. Ann. Epidemiol. 63, 52-62.

Li, X., McGue, M., Gottesman, I.I., 2012. Two sources of genetic liability to depression: interpreting the relationship between stress sensitivity and depression under a multifactorial polygenic model. Behav. Genet. 42 (2), 268-277. https://doi.org/ 10.1007/s10519-011-9506-x.

Lin, R., Money, L., Greene, S, 2020. California's Record COVID-19 Surge Persists: 51,724 Cases and 393 Deaths in a Single Day. December 16. Los Angeles Times. https ://www.latimes.com/california/story/2020-12-16/california-record-covid-surge -persists-51724-cases-393-deaths-single-day.

Loades, M.E., Chatburn, E., Higson-Sweeney, N., Reynolds, S., Shafran, R., Brigden, A. Linney, C., McManus, M.N., Borwick, C., Crawley, E., 2020. Rapid systematic review: the impact of social isolation and loneliness on the mental health of children and adolescents in the context of COVID-19. J. Am. Acad. Child Adolesc. Psychiatry. https://doi.org/10.1016/j.jaac.2020.05.009.

Long, E.E., Haraden, D.A., Young, J.F., Hankin, B.L., 2020. Longitudinal patterning of depression repeatedly assessed across time among youth: different trajectories in self-report questionnaires and diagnostic interviews. Psychol. Assess. 32 (9), 872-882. https://doi.org/10.1037/pas0000915.

Magson, N.R., Freeman, J.Y.A., Rapee, R.M., Richardson, C.E., Oar, E.L., Fardouly, J., 2020. Risk and protective factors for prospective changes in adolescent mental health during the COVID-19 pandemic. J. Youth Adolesc. https://doi.org/10.1007 s10964-020-01332-9.

Muccari, R., Chow, D., Murphy, D., 2020. Coronavirus Timeline: Tracking the Critical Moments of COVID-19. NBC News. https://www.nbcnews.com/health/health-new s/coronavirus-timeline-tracking-critical-moments-covid-19-n1154341.

Murata, S., Rezeppa, T., Thoma, B., Marengo, L., Krancevich, K., Chiyka, E., Hayes, B., Goodfriend, E., Brummit, B., Deal, M., Zhong, Y., Riston, S., Brent, D.A., Melhem, N. M., 2020. The psychiatric sequelae of the COVID-19 pandemic in adolescents, adults, and health care workers. Depress. Anxiety 1-14. https://doi.org/10.1002/da.23120.

Nesi, J., Prinstein, M.J., 2015. Using social media for social comparison and feedbackseeking: gender and popularity moderate associations with depressive symptoms. J. Abnorm. Child Psychol. 43 (8), 1427-1438. https://doi.org/10.1016/j. physbeh.2017.03.040.

O'Halloron, K., 2017. Hey Dude, Do this': the Last Resort for Female Gamers Escaping Online Abuse. October 23. The Guardian. https://www.theguardian.com/culture/ 2017/oct/24/hey-dude-do-this-the-last-resort-for-female-gamers-escaping-online-a buse.

Ohannessian, C.M., 2009. Media use and adolescent psychological adjustment: an examination of gender differences. J. Child Fam. Stud. 18 (5), 582-593. https://doi. org/10.1007/s10826-009-9261-2.

Ohannessian, C.M., 2019. Moderating effects of gender and social context. J. Affect. Disord. 15 (226), 216-219. https://doi.org/10.1016/j.jad.2017.10.009.

Osofsky, J.D., Osofsky, H.J., Weems, C.F., King, L.S., Hansel, T.C., 2015. Trajectories of post-traumatic stress disorder symptoms among youth exposed to both natural and technological disasters. J. Child Psychol. Psychiatry 56 (12), 1347-1355. https:// doi.org/10.1111/jcpp.12420.

Ostrov, B.F., Ibarra, A.B., 2020. Governor Announces New Restrictions to Curb Surging Coronavirus. November 16. CalMatters. https://calmatters.org/health/coronavir us/2020/11/california-governor-restrictions-curb-covid-19/?.

Owens, S.A., Helms, S.W., Rudolph, K.D., Hastings, P.D., Nock, M.K., Prinstein, M.J., 2019. Interpersonal stress severity longitudinally predicts adolescent girls' depressive symptoms: the moderating role of subjective and HPA axis stress responses. J. Abnorm. Child Psychol. 47 (5), 895-905. https://doi.org/10.1007/ s10802-018-0483-x.

Pollastri, A.R., Raftery-Helmer, J.N., Cardemil, E.V., Addis, M.E., 2018. Social context, emotional expressivity, and social adjustment in adolescent males. Psychol. Men Masculinity 19 (1), 69-77. https://doi.org/10.1037/men0000081.

Reuters Staff, 2020. Hospitalizations Soar in California as COVID-19 Pandemic Surges. November 10. Reuters. https://www.reuters.com/article/us-health-coronavirus-cali fornia/hospitalizations-soar-in-california-as-covid-19-pandemic-surges-idUS KBN27Q365.

Riva, G., Mantovani, F., Wiederhold, B.K., 2020. Positive technology and COVID-19. Cyberpsychol. Behav. Social Netw. 23 (9), 581-587. https://doi.org/10.1089/ cyber.2020.29194.gri.

Roberts, R.E., Lewinsohn, P.M., Seeley, J.R., 1993. A brief measure of loneliness suitable for use with adolescents. Psychol. Rep. 72, 1379-1391.

Rubens, S.L., Felix, E.D., Hambrick, E.P., 2018. A meta-analysis of the impact of natural disasters on internalizing and externalizing problems in youth. J. Trauma Stress 31 (3), 332-341. https://doi.org/10.1002/jts.22292.

Rudolph, K.D., 2002. Gender differences in emotional responses to interpersonal stress during adolescence. J. Adolesc. Health 30 (4 SUPPL. 1), 3-13. https://doi.org/ 10.1016/S1054-139X(01)00383-4.

Rudolph, K.D., 2017. Advances in conceptual and empirical approaches to understanding the interpersonal context of youth depression: commentary. J. Appl. Dev. Psychol. 51, 65-69. https://doi.org/10.1016/j.appdev.2017.05.006.

Salk, R.H., Hyde, J.S., Abramson, L.Y., 2017. Gender differences in depression in representative national samples: meta-analyses of diagnoses and symptoms. Psychol. Bull. 143 (8), 783-822. https://doi.org/10.1037/bul0000102.

Salomon, T., Cohen, A., Barazany, D., Ben-Zvi, G., Botvinik-Nezer, R., Gera, R., Oren, S., Roll, D., Rozic, G., Saliy, A., Tik, N., Tsarfati, G., Tavor, I., Schonberg, T., Assaf, Y., 2021. Brain volumetric changes in the general population following the COVID-19 outbreak and lockdown. Neuroimage 239, 118311. https://doi.org/10.1016/j. neuroimage.2021.118311.

Slavich, G.M., Giletta, M., Helms, S.W., Hastings, P.D., Rudolph, K.D., Nock, M.K., Prinstein, M.J., 2020. Interpersonal life stress, inflammation, and depression in adolescence: testing social signal transduction theory of depression HHS public access. Depress. Anxiety 37 (2), 179-193. https://doi.org/10.1002/da.22987.

Somerville, L.H., 2013. The teenage brain: sensitivity to social evaluation. Curr. Dir. Psychol. Sci. 22 (2), 121-127. https://doi.org/10.1177/0963721413476512.

Somerville, L.H., Jones, R.M., Casey, B.J., 2010. A time of change: behavioral and neural correlates of adolescent sensitivity to appetitive and aversive environmental cues. Brain Cogn. 72 (1), 124-133. https://doi.org/10.1016/j.bandc.2009.07.003.

Sprang, G., Silman, M., 2013. Posttraumatic stress disorder in parents and youth after health-related disasters. Disaster Med. Public Health Prep. 7 (1), 105-110. https:// doi.org/10.1017/dmp.2013.22.

Tapp, T. (2020, December 25). California Covid-19 update: available ICU capacity falls To 0\%. Deadline. https://deadline.com/2020/12/california-covid-19-available-ic u-capacity-falls-0-percent-1234661603/.

Thapar, A., Rutter, M., 2019. Do natural experiments have an important future in the study of mental disorders? Psychol. Med. 49 (7), 1079-1088. https://doi.org/ 10.1017/S0033291718003896.

The Coronavirus Health Impact Survey (CRISIS), 2020. http://www.crisissurvey.org/.

UN News, 2020. Reduce Risk to Avert 'Era of Pandemics' Experts Warn In New Report | October 12. https://news.un.org/en/story/2020/10/1076392.

Valenzano, A., Scarinci, A., Monda, V., Sessa, F., Messina, A., Monda, M., Precenzano, F., Mollica, M.P., Carotenuto, M., Messina, G., Cibelli, G., 2020. The social brain and emotional contagion: covid-19 effects. Medicina 56 (12), 1-10. https://doi.org/ 10.3390/medicina56120640.

Vanhalst, J., Luyckx, K., Teppers, E., Goossens, L., 2012. Disentangling the longitudinal relation between loneliness and depressive symptoms: prospective effects and the intervening role of coping. J. Soc. Clin. Psychol. 31 (8), 810-834. https://doi.org/ 10.1521/jscp.2012.31.8.810.

Vannucci, A., McCauley Ohannessian, C., 2019. Social media use subgroups differentially predict psychosocial well-being during early adolescence. J. Youth Adolesc. 48 (8), 1469-1493. https://doi.org/10.1007/s10964-019-01060-9.

WHO, 2020. Archived: WHO Timeline-COVID-19. https://www.who.int/news/item/2704-2020-who-timeline-covid-19. 17 April WHO.

WHO Coronavirus Disease (COVID-19) Dashboard. (2021). https://covid19.who.int/.

Zhang, L., Zhang, D., Fang, J., Wan, Y., Tao, F., Sun, Y., 2020. Assessment of mental health of chinese primary school students before and after school closing and opening during the COVID-19 pandemic. JAMA Netw. Open 3 (9). https://doi.org/ 10.1001/jamanetworkopen.2020.2148. 